\title{
Passive Whole-Body Hyperthermia Increases Aerobic Capacity and Cardio-Respiratory Efficiency in Amateur Athletes
}

\author{
Maxim A. Zapara1, Elena N. Dudnik1, Vlada G. Samartseva1, Svetlana Yu. Kryzhanovskaya1, \\ Davide Susta², Oleg S. Glazachev ${ }^{1}$ \\ ${ }^{1}$ Department of Normal Physiology, I. M. Sechenov First Moscow State Medical University (Sechenov University), \\ Moscow, Russia \\ ${ }^{2}$ School of Health and Human Performance, Dublin City University, Dublin, Ireland \\ Email: glazachev@mail.ru
}

How to cite this paper: Zapara, M.A., Dudnik, E.N., Samartseva, V.G., Kryzhanovskaya, S.Y., Susta, D. and Glazachev, O.S. (2020) Passive Whole-Body Hyperthermia Increases Aerobic Capacity and Cardio-Respiratory Efficiency in Amateur Athletes. Health, 12, 14-26.

https://doi.org/10.4236/health.2020.121002

Received: November 1, 2019

Accepted: January 4, 2020

Published: January 7, 2020

Copyright $\odot 2020$ by author(s) and Scientific Research Publishing Inc. This work is licensed under the Creative Commons Attribution-NonCommercial International License (CC BY-NC 4.0). http://creativecommons.org/licenses/by-nc/4.0/

\begin{abstract}
Objective: The research was carried out to test the influence of adaptation to passive whole body hyperthermia $(\mathrm{PH})$ on physical capacity and cardio-respiratory efficiency in men-amateur athletes under the testing load of increasing intensity in laboratory thermal-neutral conditions. Twenty-eight amateur athletes (males, mean age $20.2 \pm 2.1$ y.o., game-based kinds of sports—football, handball, training experience $-4-7$ years) were randomized into two groups: experimental (14 people), who underwent $24 \mathrm{PH}$ procedures, and control (14 people), who underwent 24 light training sessions in interval regime on elliptical gym apparatus. Results: Adaptation to PH was accompanied by moderate increase of aerobic efficiency and cardio-respiratory endurance in amateur athletes under thermally neutral conditions, while interval training in the control group showed no reliable changes in efficiency. Conclusion: A 10-week course of $\mathrm{PH}$ procedures leads to the increase of peak oxygen consumption, oxygen consumption at the level of anaerobic threshold, and heart efficiency (enhancement of oxygen pulse values), as well as efficiency of pulmonary ventilation and bronchial conductance, which we consider to be cross effects of adaptation to passive whole-body repetitive hyperthermia.
\end{abstract}

\section{Keywords}

Adaptation, Amateur Athletes, Endurance, Passive Whole-Body

Hyperthermia, Aerobic Capacity

\section{Introduction}

Heat acclimatization (HA) as a method of increasing athletes' efficiency for fur- 
ther training and competition activity in hot climate is well-grounded and widely used in training athletes of various kinds of sports [1] [2] [3]. HA is developed during repeated combined exposure of a body to moderate stressors: physical load (endogenous metabolic stressor, increasing the temperature of the body core) under high temperature of the environment $\left(28^{\circ} \mathrm{C}-33^{\circ} \mathrm{C}\right.$-exogenous stressor, increasing the skin temperature) [4]. Such approach is based on the concept of adaptation syndrome development and the phenomenon of direct and cross adaptation effects. It is postulated that adaptation to a certain stress factor of the environment leads to increased tolerance to this stressor and resistance to other stress impacts [5] [6] [7].

Various protocols of using other factors (in addition to HA) have been proposed (hypoxia, high air humidity etc.) in order to launch the cross adaptation effects and increase the aerobic endurance of athletes under the conditions of middle altitude, high temperature, or neutral thermal conditions [7]-[12]. However, the results of these researches are rather contradictory and hard to compare, as they use different methods. For example, S. Lorenzo et al. [13] showed that $\mathrm{HA}$ of bicyclists of intermediate level of training ( 10 days by 90 minutes of intense training under hot climate $30^{\circ} \mathrm{C}$ ) leads to $5 \%-8 \%$ enhancement of the results of laboratory testing of a 1 hour race, as well as to an increase of maximal oxygen consumption $\left(\mathrm{VO}_{2} \max \right)$, and anaerobic threshold (AT) under the external temperature of $13^{\circ} \mathrm{C}$. Other researchers showed that HA of bicycle racers or track and field athletes, with triathletes of high level at the peak of their sports shape leads to increasing their sports results tested in hot climate, but is not accompanied by the increase of efficiency, peak values of oxygen consumption under intermediate temperatures $\left(17^{\circ} \mathrm{C}-20^{\circ} \mathrm{C}\right)$, or neutral thermal conditions in combination with hypoxia [14] [15].

Heat acclimatization results are also hard to interpret as two stressors-exercise and high temperature-act simultaneously, which does not allow estimating the contribution of each into the further increase of the athlete's performance and/or cardio-respiratory efficiency under neutral thermal conditions.

As for researching the influence of adaptation to isolated repeated passive hyperthermia (without training load) on aerobic endurance, the $\mathrm{VO}_{2}$ max values of athletes were not fully developed, though there are certain grounds for that. For example, one of the key cellular mechanisms of adaptation to hyperthermia, or HA, is production of heat shock proteins (HSP72, HSP90) and hypoxia-induced factor (HIF1a), stabilization and activation of which may also take place under normal oxygen conditions under the influence of HSP90 and reactive oxygen species (ROS) [16] [17]. Expression of HSP synthesis is closely connected with the increase of the body core temperature and stimulates the processes of vasodilation, the skin and muscle blood flow, while HIF1a, in turn, launches the processes of angiogenesis, erythropoiesis, stimulates production of growth factors, glycolytic enzymes, nitrogen monoxide, molecules with antioxidant properties, etc. [4] [6]. As a result, systemic ergogenic mechanisms of hyperthermia adaptation are launched, including increase of myocardium efficiency, cardiac 
output, increasing the volume of blood plasma, the threshold of lactate tolerance, optimizing the endothelial function, autonomous regulation, thermoregulatory transformations-decreasing the temperature threshold of perspiration, increasing its efficiency under the same growth rates of the body core temperature [3] [4] [18] [19].

Positive effects of adaptation to passive isolated hyperthermia are confirmed by the experience of regular ( 1 - 2 times a week) prolonged application of dry-air or infrared saunas [18] [20] [21]. This is accompanied by decreasing the risk of cardiovascular pathology, normalizing the high arterial blood pressure, carbohydrate and lipid metabolism, and increasing the level of physical efficiency in healthy non-trained middle-aged volunteers [17] [20] [22].

In the present research, we supposed to estimate the influence of adaptation to passive whole-body hyperthermia to cardio-respiratory endurance and aerobic efficiency when performing the testing load of increasing intensity under laboratory conditions in comfortable external temperature. The research hypothesis is as follows: adaptation to passive repeated whole-body hyperthermia increases exercise tolerance in indicators of peak oxygen consumption and cardio-respiratory endurance in men-amateur athletes tested under thermally neutral conditions.

\section{Research Methods and Organization}

The randomized controlled study comprised 28 amateur athletes (males, average age $20.2 \pm 2.1$ y.o., games-based sports-football, handball, duration of doing sports -4 - 7 years). The research protocol was formed in compliance with the provisions of "Bioethical rules of human research", conformed to the standards set by the Declaration of Helsinki and approved by the Bioethics Commission of the University (Protocol 05-19 from April, 10 ${ }^{\text {th }}, 2019$ ). All respondents gave their written informed consent prior to the examination. The study was registered at Clinical Trials.gov (ID: NCT04089410).

After preliminary medical checkup (in order to exclude chronic pathology), all participants were divided into two groups (block randomization 1:1 in blocks by 6 based on randomization list): experimental group (EG, 14 people), who later underwent 24 procedures of passive whole-body hyperthermal adaptation, and control group (CG, 14 people), who underwent 24 training sessions with elliptical gym apparatus in interval regime. The athletes of the two groups did not differ by the key demographic and anthropometric characteristics (Table 1 ), they did not use any medications 2 weeks before and the whole study period.

\subsection{Hyperthermic Procedures and Interval Training}

The EG athletes underwent a course of passive hyperthermal adaptation using a capsule Alfa Basic (Sybaritic Inc., Minnesota, USA). The capsule is an ergonomic camera in which an athlete may take a lying position and undergo whole-body hyperthermia procedures (infrared heating), the head being outside the camera blown by cool air with a built-in ventilator. Preliminarily, all EG participants 
Table 1. Key demographic characteristics of the research participants.

\begin{tabular}{ccc}
\hline Indicators & EG $(\mathrm{n}=14)$ & CG $(\mathbf{n}=11)$ \\
\hline Age, years & $20.7 \pm 2.3$ & $20.0 \pm 0.3$ \\
Body mass, $\mathrm{kg}$ & $78.7 \pm 13.4$ & $73.4 \pm 10.6$ \\
Body length, cm & $182.8 \pm 9.8$ & $179.3 \pm 7.8$ \\
Body mass index, $\mathrm{kg} / \mathrm{m}^{2}$ & $23.7 \pm 3.1$ & $22.6 \pm 2.9$ \\
Smoking $(8-12$ cigarettes per day) & $9(64.3 \%)$ & $4(36.4 \%)$ \\
Taking medications & $14.3 \%(\mathrm{n}=2)$ & $9.1 \%(\mathrm{n}=1)$ \\
SpO & $\%$ & $98.1 \pm 2.1$ \\
Heart rate at rest (HR), bpm & $97.9 \pm 1.05$ & $70.0 \pm 8.9$ \\
Systolic arterial pressure, $\mathrm{mmHg}$ & $68.2 \pm 10.7$ & $125.1 \pm 8.9$ \\
Diastolic arterial pressure, $\mathrm{mmHg}$ & $126.8 \pm 13.4$ & $79.4 \pm 6.7$ \\
\hline
\end{tabular}

Legend: EG-experimental group, $\mathrm{CG}-$ control group, the data are represented as mean $\pm \mathrm{SD}$ or $\mathrm{n} / \mathrm{N}$ (\%).

underwent a testing hyperthermia procedure (HP) in the capsule, with increasing of temperature from $40^{\circ} \mathrm{C}$ by $10^{\circ} \mathrm{C}$ each 10 minutes till the individual subjective tolerance threshold is achieved, then the body core temperature was measured. Further, the parameters of hypermetric adaptation procedures were selected individually by the results of the testing procedure. On average, the temperature in the capsule was established at $65^{\circ} \mathrm{C}-80^{\circ} \mathrm{C}$, while the temperature of the athlete's body core by the end of the procedure increased by $1.5^{\circ} \mathrm{C}-2.0^{\circ} \mathrm{C}$. The recommended duration of one procedure was 40 minutes, but not all athletes endured such duration, thus the first procedures of some participants according to individual self-reports were reduced up to 25 - 30 minutes.

In general, each EG participant underwent 24 hyperthermia procedures in the following regime: the first period-3 sessions a week every second day, total 12 procedures in 4 weeks; the second period-2 sessions a week, 12 procedures in 6 weeks. All athletes were recommended to attend the procedures in a hydrated enough state, not less than three hours after meals and caffeine intake, not to change the dietary and training pattern during the research period (2 play trainings a week, on the days when the athletes did not undergo hyperthermia procedures).

As any influence would be obviously eliminated in case of attempting to organize placebo procedures in the thermal capsule, the CG participants were invited to the laboratory at the same periods and with the same frequency as the EG athletes. The former underwent training on elliptical gym apparatus HouseFit N-300 (China) in interval regime: moderate loads (45\% - 55\% from the individual values of HR max) during 6 - 7 minutes were interchanged for rest periods (treadling with $25 \%-30 \%$ load of HR max). Duration of each interval training (IT) session was 40 minutes, total 24 trainings in 10 weeks.

Before and immediately after each HP/IT, the following measurements were made for each athlete still within the capsule (sitting on the elliptical gym appa- 
ratus): heart rate (HR), systolic and diastolic arterial pressure (SAP and DAP, automatic tonometer AND UA-767, AND, Japan), body core temperature (infrared thermometer AND DT-635, AND, Japan) as a mean of double measurements in both axillary regions. Besides, in the dynamics of each procedure we monitored the blood saturation with oxygen $\left(\mathrm{SpO}_{2}\right)$ and $\mathrm{HR}$ with a pulse-oxymeter MD300 (BCE Tech, China).

\subsection{Estimating the Parameters of Body Composition, Peak Oxygen Consumption and Cardio-Respiratory Endurance}

Initially, after 12 procedures of hyperthermia (interval trainings) and after a 10-week cycle of HP/IT (after 24 procedures) we estimated the parameters of the body composition with a portable bio-impendance meter Tanita BC-601 (Tanita, Japan), calculating the muscle mass in $\mathrm{kg}$ and fat mass in \% to the total body mass.

In the same period, all participants underwent a cardiopulmonary exercise test (CPET) on a treadmill with measuring of oxygen uptake (gas analyzer Fitmate MED (COSMED, Italy) and a running machine Intertrack (Shiller, Switzerland)) by BRUCE protocol (step load of increasing intensity up to refusal, duration of each step 3 minutes (initial speed $1.7 \mathrm{mph}$ increasing to 2.5, 3.4, 4.2, 5.0 and 5.5 mph, initial angle of the running track $10^{\circ}$ increased at each step by $2^{\circ}$ [23] [24]. The choice of relatively "light" and short protocol of load testing was due to the fact that the study participants were amateur athletes without special training in endurance, with initial values of $\mathrm{VO}_{2}$ max at the level of healthy people-non-athletes. All participants preliminarily underwent familiarization with testing procedure; the gas analyzer was calibrated before each testing.

Prior to doing the load testing, we estimated the breathing function, registering the following indicators: forced vital capacity (FVC), forced expiratory volume in the first sec (FEV1), peak expiratory flow (PEF), mean expiratory flow at the levels of large, middle, and small bronchi (MEF-75\%, MEF-50\%, and MEF-25\%, respectively).

In the test dynamics, the HR values were monitored continuously with the sensors of a breast strap Polar 610i (Finland), the signal of an optoelectronic sensor in the mask as transmitted to the gas analyzer. The values of all registered indicators were averaged for each 15-second interval [24] We applied criteria for the testing termination corresponding to recommendations [23]. Borg scale was used to objectify the subjective self-reports on the load. On average, the test was completed in 14 - 15 minutes.

When analyzing the dynamics of aerobic efficiency and cardio-respiratory endurance, the following indicators were taken into account: maximal HR (HRmax), \% of HRmax from predicted individual values, blood pressure increase at each stage of load, at maximal load, and during restoration period, peak oxygen uptake $\left(\mathrm{VO}_{\text {2peak }}\right), \% \mathrm{VO}_{\text {ppeak }}$ from predicted values $\left(\mathrm{VO}_{2 \text { peak }}\right.$, \%), oxygen uptake at the level of anaerobic (ventilator) threshold $\left(\mathrm{VO}_{2} \mathrm{AT}\right), \%$ of $\mathrm{VO}_{2} \mathrm{AT}$ 
from predicted values $\left(\mathrm{VO}_{2} \mathrm{AT}, \%\right)$, respiratory frequency (Rf), peak pulmonary ventilation (VE), oxygen pulse $\left(\mathrm{VO}_{2}\right.$ peak/HRmax), ventilatory equivalent of oxygen $\left(\mathrm{VE} / \mathrm{VO}_{2}\right.$ peak). All testing was carried out in a laboratory premises at the temperature of $21^{\circ} \mathrm{C}-23^{\circ} \mathrm{C}$.

\subsection{Statistical Methods}

The data were analyzed with Statistica 11.0 software. The data are represented as a mean and standard deviation $(\mathrm{M} \pm \mathrm{SD})$. Checking for normal distribution was carried out with Kolmogorov-Smirnov test; to estimate the significance of intraand inter-group differences in dynamics, we used one-sample t-test, Wilcoxon test (for intra-group comparisons) and Mann-Whitney test (for inter-group comparisons). The differences were considered significant at $\mathrm{p}<0.05$.

\section{Results}

Of 28 athletes involved in the research, 23 people competed the full cycle (2 people from EG and 3 people from CG were excluded due to acute respiratory viral infection ( 2 people) and low compliance with the research protocol ( 3 men). All athletes satisfactorily endured the procedures of passive whole-body hyperthermia and interval training. The typical reaction of the EG participants to hyperthermia was significant increase of the body core temperature (Tc) by $2.0^{\circ} \mathrm{C}$ on average with individual variations from $1.2^{\circ} \mathrm{C}$ to $5.5^{\circ} \mathrm{C}$ by the end of the procedure (Table 2). At that, a typical hemodynamic response was detected, in the form of decreased SAP and DAP and increase of HR up to the values compared to the HR under moderate physical load (55\% - 65\% of HRmax), as well as significant decrease of $\mathrm{SpO}_{2}$ value by the end of hyperthermia in virtually all procedures (from the $1^{\text {st }}$ to the $24^{\text {th }}$ ), which reflects the increase of oxygen extraction by the tissues. In CG during IT, no significant shifts of Tc and $\mathrm{SpO}_{2}$ were observed while SAP and Dap increased to the values corresponding to the low and moderate load (Table 2).

By the results of initial testing, the EG and CG athletes did not significantly differ from each other by the level of aerobic efficiency, the values of cardio-respiratory economy, and of pulmonary ventilation. In the dynamics of the 10-week cycle of interval trainings in supporting regime (low degree), CG participants demonstrated no significant dynamics of the indicators of aerobic efficiency, pulmonary ventilation and bronchial conductance (Table 3 and Table 4).

After $12 \mathrm{HP}$ procedures, EG athletes demonstrated significant increase in the exercise time up to fatigue, the values of the initially reduced oxygen uptake at the level of anaerobic threshold in relation to control group-by $16.3 \% \pm 12.0 \%$ under significant hyperventilation response (increase of VE by $15 \% \pm 21.7 \%$, $\mathrm{Rf}$-by $15.9 \% \pm 21.7 \%$, while the values of ventilator equivalent $\mathrm{VE} / \mathrm{VO}_{2}$ peak exceeded the control group values).

After 24 procedures in EG, under reliably longer exercise time up to exhaustion compared to the CG, we marked reliable increase of aerobic efficiency-absolute and relative $\mathrm{VO}_{2}$ peak (\% from predicted values) - by $12.5 \% \pm 8.3 \%$ 
Table 2. Average dynamics of physiological indicators before and after hyperthermic procedures (HP)/interval training (IT).

\begin{tabular}{|c|c|c|c|c|c|c|}
\hline Group & & $\mathrm{EG}, \mathrm{n}=12$ & & & $\mathrm{CG}, \mathrm{n}=11$ & \\
\hline Indicators & before HP & after HP & $\begin{array}{c}\text { difference } \\
\text { before and } \\
\text { after HP }\end{array}$ & before IT & after IT & $\begin{array}{c}\text { difference } \\
\text { before and } \\
\text { after IT }\end{array}$ \\
\hline $\begin{array}{c}\text { Body core } \\
\text { temperature, } \mathrm{Tc},{ }^{\circ} \mathrm{C}\end{array}$ & $36.4 \pm 0.1$ & $38.5 \pm 0.3$ & $+2.0 \pm 0.4$ & $36.4 \pm 0.1$ & $36.3 \pm 0.4$ & $\begin{array}{l}-0.08 \pm 0.2 \\
* * p=0.005\end{array}$ \\
\hline $\mathrm{SAP}, \mathrm{MmHg}$ & $123.8 \pm 10.6$ & $112.1 \pm 10.4$ & $-11.7 \pm 5.9$ & $122.7 \pm 9.7$ & $127.2 \pm 8.2$ & $5.6 \pm 4.8$ \\
\hline DAP, $\mathrm{MmHg}$ & $72.6 \pm 7.1$ & $56.7 \pm 5.2$ & $-15.8 \pm 6.0$ & $70.0 \pm 5.7$ & $67.9 \pm 7.5$ & $\begin{array}{l}-2.0 \pm 5.1 \\
{ }^{* *} \mathrm{p}=0.02\end{array}$ \\
\hline Heart rate, bpm & $83.9 \pm 7.9$ & $125.9 \pm 16.2$ & $42 \pm 15.1$ & $83.2 \pm 8.6$ & $113.9 \pm 11.2$ & $30.6 \pm 14.0$ \\
\hline $\mathrm{SpO}_{2}, \%$ & $96.9 \pm 0.4$ & $95.8 \pm 0.6$ & $-1.1 \pm 0.7$ & $96.9 \pm 0.3$ & $96.2 \pm 0.5$ & $-0.6 \pm 0.4$ \\
\hline
\end{tabular}

Note: average data of all participants' responses to each of 24 hyperthermic procedures (HP) for experimental group and interval trainings (IT) for control group. ${ }^{*}$ Significance of differences in changes of indicators before and after HP and before and after IT.

Table3. Results of exercise testing in the course of hyperthermic procedures (HP)/interval training (IT).

\begin{tabular}{|c|c|c|c|c|}
\hline Indicator & Group & Initially & After 12 procedures & After 24 procedures \\
\hline \multirow{2}{*}{$\begin{array}{l}\mathrm{VO}_{2} \text { peak, } \\
\mathrm{ml} / \mathrm{min}\end{array}$} & EG & $3061 \pm 491$ & $3252 \pm 474$ & $3382 \pm 383^{* *}(\mathrm{p}=0.02)$ \\
\hline & CG & $3009 \pm 565$ & $2818 \pm 496^{*}(\mathrm{p}=0.05)$ & $2801 \pm 608^{\#}(\mathrm{p}=0.02)$ \\
\hline \multirow{2}{*}{$\mathrm{VO}_{2}$ peak, $\%$} & EG & $93.9 \pm 10.6$ & $97.4 \pm 11.6$ & $98.7 \pm 11.8^{*}(\mathrm{p}=0.04)$ \\
\hline & CG & $97.6 \pm 13.1$ & $96.0 \pm 7.7$ & $91.0 \pm 11.9$ \\
\hline \multirow{2}{*}{$\mathrm{VO}_{2}$ peak/BM } & EG & $39.6 \pm 4.5$ & $41.1 \pm 4.9$ & $42.6 \pm 3.4^{*}(\mathrm{p}=0.05)$ \\
\hline & CG & $41.2 \pm 5.5$ & $40.5 \pm 3.2$ & $38.0 \pm 5.0$ \\
\hline \multirow{2}{*}{$\mathrm{VE}, \mathrm{L} / \mathrm{min}$} & EG & $101.3 \pm 17.7$ & $114.9 \pm 20.0^{*}(\mathrm{p}=0.02)$ & $121.1 \pm 12.9^{*}(\mathrm{p}=0.01)$ \\
\hline & CG & $99.2 \pm 27.5$ & $92.6 \pm 27.2$ & $98.3 \pm 32.8^{\#}(\mathrm{p}=0.05)$ \\
\hline \multirow{2}{*}{$\mathrm{Rf}, \mathrm{resp} / \mathrm{min}$} & EG & $40 \pm 8.9$ & $44.8 \pm 6.2^{*}(\mathrm{p}=0.01)$ & $42.6 \pm 10.2$ \\
\hline & CG & $40.7 \pm 10.1$ & $38.2 \pm 10.0^{*}(\mathrm{p}=0.05)$ & $40.9 \pm 9.0$ \\
\hline \multirow{2}{*}{ HRmax, bpm } & EG & $180.7 \pm 11.4$ & $183.5 \pm 10.0$ & $179.8 \pm 13.1$ \\
\hline & CG & $175.8 \pm 17.1$ & $176.5 \pm 12.3$ & $169.6 \pm 17.2$ \\
\hline \multirow{2}{*}{ HRmax, \% } & EG & $90.3 \pm 5.2$ & $91.7 \pm 5.0$ & $89.9 \pm 6.8$ \\
\hline & CG & $87.3 \pm 8.5$ & $87.6 \pm 6.3$ & $84.2 \pm 8.5$ \\
\hline \multirow{2}{*}{$\mathrm{VO}_{2} \mathrm{AT} / \mathrm{BM}$} & EG & $18.9 \pm 2.4$ & $21.9 \pm 2.8^{*}(\mathrm{p}=0.004)$ & $22.5 \pm 2.2^{*}(\mathrm{p}=0.002)$ \\
\hline & CG & $21.9 \pm 2.8^{\#}(\mathrm{p}=0.03)$ & $21.5 \pm 4.4$ & $20.9 \pm 3.5$ \\
\hline \multirow{2}{*}{$\mathrm{VO}_{2} \mathrm{AT}, \%$} & EG & $48.0 \pm 5.9$ & $53.7 \pm 7.6^{\star}(\mathrm{p}=0.004)$ & $54.4 \pm 6.3^{*}(\mathrm{p}=0.01)$ \\
\hline & CG & $53.8 \pm 8.6$ & $53.6 \pm 13.4$ & $55.5 \pm 11.0$ \\
\hline \multirow{2}{*}{$\begin{array}{c}\mathrm{VO}_{2} \\
\text { peak/HRmax } \\
\mathrm{ml} / \mathrm{bpm}\end{array}$} & EG & $16.9 \pm 2.4$ & $17.7 \pm 2.4$ & $18.9 \pm 2.5^{\star}(\mathrm{p}=0.01)$ \\
\hline & CG & $17.4 \pm 4.8$ & $16.0 \pm 2.6$ & $16.5 \pm 3.0^{\#}(\mathrm{p}=0.05)$ \\
\hline \multirow{2}{*}{$\mathrm{VE} / \mathrm{VO}_{2}$ peak } & EG & $25.6 \pm 3.4$ & $28.0 \pm 4.5$ & $28.5 \pm 3.1$ \\
\hline & CG & $24.0 \pm 5.2$ & $22.8 \pm 6.0^{\sharp}(\mathrm{p}=0.05)$ & $25.4 \pm 6.1$ \\
\hline \multirow{2}{*}{$\begin{array}{l}\text { exercise time to } \\
\text { exhaustion }\end{array}$} & EG & $946 \pm 189$ & $1089 \pm 119^{*}(\mathrm{p}=0.03)$ & $1089 \pm 97^{\star}(\mathrm{p}=0.03)$ \\
\hline & CG & $1035 \pm 69$ & $1036 \pm 26$ & $991 \pm 121^{\#}(\mathrm{p}=0.03)$ \\
\hline
\end{tabular}

Note: ${ }^{*}$ Significance of differences in relation to the initial testing data in the same group; ${ }^{*}$ Significance of inter-group differences at one stage of testing. 
Table 4. Indicators of body composition and pulmonary ventilation in the course of hyperthermic procedures (HP)/interval training (IT).

\begin{tabular}{|c|c|c|c|c|}
\hline Indicators & Group & Initially & After $12 \mathrm{HP} / \mathrm{IT}$ & After24 HP/IT \\
\hline \multirow{2}{*}{$\begin{array}{l}\text { Body mass index, } \\
\qquad \mathrm{kg} / \mathrm{m}^{2}\end{array}$} & EG & $24.1 \pm 3.1$ & $24.2 \pm 3.2$ & $24.4 \pm 3.3$ \\
\hline & CG & $22.7 \pm 3.0$ & $22.3 \pm 2.4$ & $22.5 \pm 2.3$ \\
\hline \multirow{2}{*}{ Muscle mass, kg } & EG & $64.3 \pm 9.0$ & $64.9 \pm 8.0$ & $65.8 \pm 8.3^{*}(\mathrm{p}=0.036)$ \\
\hline & CG & $62.4 \pm 7.7$ & $62.1 \pm 8.2$ & $62.1 \pm 8.3$ \\
\hline \multirow{2}{*}{ Fat mass, \% } & EG & $12.8 \pm 4.1$ & $12.4 \pm 5.1$ & $13.3 \pm 5.3$ \\
\hline & CG & $9.7 \pm 3.2$ & $10.0 \pm 3.3$ & $10.2 \pm 3.7$ \\
\hline \multirow{2}{*}{ FVC, 1} & EG & $5.3 \pm 0.8$ & $5.3 \pm 0.5$ & $5.5 \pm 0.5$ \\
\hline & CG & $4.7 \pm 1.0$ & $4.7 \pm 0.9^{\#}(\mathrm{p}=0.02)$ & $4.7 \pm 1.0^{\#}(\mathrm{p}=0.03)$ \\
\hline \multirow{2}{*}{ FEV1, 1} & EG & $4.5 \pm 0.7$ & $4.8 \pm 0.5$ & $5.0 \pm 0.4^{*}(\mathrm{p}=0.009)$ \\
\hline & CG & $4.3 \pm 0.7$ & $4.4 \pm 0.8^{\#}(\mathrm{p}=0.02)$ & $4.4 \pm 0.7^{\#}(\mathrm{p}=0.015)$ \\
\hline \multirow{2}{*}{$\mathrm{PEF}, 1 / \mathrm{sec}$} & EG & $8.0 \pm 1.4$ & $9.1 \pm 1.2^{\star}(\mathrm{p}=0.02)$ & $9.3 \pm 1.2^{*}(\mathrm{p}=0.03)$ \\
\hline & CG & $8.3 \pm 1.8$ & $8.1 \pm 2.0$ & $8.1 \pm 1.4$ \\
\hline \multirow{2}{*}{ MEF-75\% } & EG & $6.5 \pm 1.9$ & $8.2 \pm 1.4^{*}(\mathrm{p}=0.007)$ & $8.5 \pm 1.3^{*}(p=0.02)$ \\
\hline & CG & $7.5 \pm 1.5$ & $7.4 \pm 1.3$ & $7.3 \pm 1.1^{\#}(\mathrm{p}=0.007)$ \\
\hline \multirow{2}{*}{ MEF- $50 \%$} & EG & $4.8 \pm 1.7$ & $5.7 \pm 1.2$ & $6.1 \pm 1.2^{\star}(\mathrm{p}=0.06)$ \\
\hline & CG & $6.0 \pm 0.6$ & $5.8 \pm 0.8$ & $6.1 \pm 1.1$ \\
\hline \multirow{2}{*}{ MEF-25\% } & EG & $2.8 \pm 1.2$ & $3.2 \pm 0.9$ & $3.8 \pm 0.9^{*}(\mathrm{p}=0.03)$ \\
\hline & CG & $3.6 \pm 0.5^{\#}(\mathrm{p}=0.05)$ & $3.3 \pm 0.4$ & $3.8 \pm 0.9$ \\
\hline
\end{tabular}

Note: ${ }^{\star}$ Significance of differences in relation to the initial testing data in the same group.

and $8.1 \% \pm 9.0 \%$ respectively, further increase of $\mathrm{VO}_{2}$ at $\mathrm{AT}$, and increase of the $\mathrm{O}_{2}$ pulse indicator $\left(\mathrm{VO}_{2}\right.$ peak/HRmax $)$, reflecting cardiac performance. At that, the significantly higher ventilator response to exercise (VE) was preserved, while no changes in chronotropic reaction to exercise were detected.

In the dynamics of the course of passive adaptation to hyperthermia, we marked a significant (in contrast to the control group) increase pulmonary expiratory parameters-FEV1, PEF, MEF-75\%, MEF-50\%, MEF-25\%, which reflects the better conductance of bronchi of various calibers-from large to small ones (Table 4). No reliable changes of the body composition in the study dynamics were detected in both experimental and control groups (despite rather intense sessions of heating of the EG athletes).

\section{Discussion}

For the first time, the research shows that adaptation to a course of passive whole-body hyperthermia sessions leads to moderate increase of aerobic efficiency and cardio-respiratory endurance in men-amateur athletes performing a treadmill exercise test up to exhaustion under thermally neutral conditions.

In a large number of studies, heat acclimatization (training intensity from 1.5 to 4 hours in hot climate $-29^{\circ} \mathrm{C}-33^{\circ} \mathrm{C}$ ) was used to increase efficiency and physical endurance in athletes of various specializations and levels of training, 
both under hot and moderate climate [1] [9] [10] [25]. In our study we applied a protocol of prolonged passive whole-body intense (temperature in the thermo-capsule increased up to $75^{\circ} \mathrm{C}-80^{\circ} \mathrm{C}$ ) hyperthermia to eliminate the potential additional (in relation to thermal stress) effects of the exercise intense training per se (metabolic stress), which is used in the research of thermal adaptation effects on efficiency in elite athletes.

It was revealed that a 10-week course of passive hyperthermia in the selected regime leads to the increase of aerobic efficiency, peak oxygen consumption, oxygen consumption at the level of anaerobic threshold, and heart efficiency (enhancement of oxygen pulse values).

The control group, consisting of participants of the same level of sports training who attended the laboratory in the same regime to perform interval exercise of moderate intensity, did not show reliable changes of the analyzed indicators; thus, we consider that the leading factor of the revealed adaptive changes was the effect of hyperthermic stress.

It is recognized that to launch the thermoregulatory adaptive processes, significant for adaptation to metabolic stressors (loads) it is necessary to increase the body core temperature by $1.5^{\circ} \mathrm{C}-2.0^{\circ} \mathrm{C}$ [4] [6]; this exactly served as a key factor of dosing whole-body hyperthermic sessions in our work.

The marked "ergogenic" effect of adaptation to passive hyperthermia can be partially explained by a number of morpho-functional shifts launched by the repeated procedures which increase the body core temperature and facilitating the adaptation to metabolic stress (exercising up to refusal): improved cardiac efficiency due to moderate decrease of arterial pressure and post-load; increase of skin and muscle blood flow and blood plasma volume; reducing the submaximal values of HR; stimulation of oxygen extraction by muscles due to more intense oxyhemoglobin dissociation; stimulation of capillarization; increase of the capacity of anti-oxidant mechanisms; and stimulation of nitrogen monoxide production as a modulator of oxygen-dependent processes in the body (oxygen-transportation function of blood, prooxidant-antioxidant balance) [8] [19] [26] [27].

There are indirect proofs of increasing exercise tolerance under normal thermal conditions after passive hyperoxic conditioning: reduced oxygen consumption, lower values of lactate, blood plasma potassium, when the athletes performed loads of the same degrees of intensity as before the course of heat adaptation [4].

For understanding the hyperthermically conditioned adaptive changes, it is important to consider the result of our study showing increases in peak exercise pulmonary ventilation, as well as the values of resting bronchial conductivity after the course of heating sessions. This can be viewed as a mechanism of adaptation to repeated hyperthermia, not as a reduction of load efficiency, and is concordant with the data by A. E. Beaudin et al. [28]. The authors of the above research showed that the increased pulmonary ventilation (exceeding metabolic needs) after a course of 10 passive hyperthermia procedures was due to the de- 
creased temperature threshold (lower gradient of the increase of body core temperature) of the ventilatory response, similar to the decrease of sweating threshold. This is a component of thermolytic efferent "response" to recurrent hyperthermia episodes, launched from preoptic hypothalamic nuclei, and not a consequence of the respiratory center increased sensitivity to $\mathrm{CO}_{2}$ [8] [20] [28].

The revealed changes of bronchial conductivity cannot be due to stimulation of thermo-receptors of respiratory tracts, as in our research the head of an athlete was outside the capsule during hyperthermia session and was not exposed to heating, and they breathed with the air of neutral temperature. The potential factors of improving the pulmonary ventilation and bronchial conductivity at rest after the course of hyperthermia can be normalization of nitrogen monoxide production dynamics in the lung parenchyma, which influences the pulmonary blood flow and ventilation, as well as a certain training of respiratory muscles during hyperthermic impacts [19] [29]. However, these assumptions require further studies.

The study results may have practical value, as they substantiate the application of passive whole-body hyperthermia procedures for potentiating exercise capacity and cardio-respiratory efficiency in amateur athletes (in addition to sports training) with low/intermediate indicators of aerobic efficiency at the initial stages of training cycle, as well as in athletes after traumas to maintain their aerobic capacity and cardio-respiratory efficiency. Additional research would help to elaborate the optimal combinations of consecutive application of sports training and passive hyperthermia, which is considered to be rather promising [16].

\section{Research Limitations and Prospects}

The obtained results of hyperthermically conditioned increase of aerobic efficiency of amateur athletes under thermally neutral conditions are preliminary. The research limitations include the small size of the studied sample and the lack of placebo group, the latter being the athletes staying in the capsule without temperature influence. Significant individual variations of adaptive responses in men-amateur athletes to passive hyperthermia suggest that there are individuals tolerant and sensitive to hyperthermia. This requires elaboration of criteria and indicators for determining and predicting the effects of passive whole-body hyperthermic adaptation.

Further research are necessary to translate the obtained results to groups of professional athletes of higher qualification, as well as to elaborate the most effective protocols of passive hyperthermic conditioning in the practice of qualified athletes training and sports medicine.

\section{Conclusions}

It is shown that prolonged adaptation to passive hyperthermia (without exercising) leads to increasing the aerobic capacity of men-amateur athletes tested un- 
der thermal-neutral conditions. A course of passive hyperthermic acclimation leads to the increase of peak oxygen uptake, oxygen uptake at the level of anaerobic/ventilatory threshold, and heart efficiency.

Pulmonary ventilation increases and, accordingly, the ventilatory equivalent at peak exercise after hyperthermic adaptation is not a symptom of reduction in respiratory efficiency when performing exercise, but is most probably a sign of adaptation to hyperthermic repeated stressors.

Additional studies are required to reveal the cross-effects of adaptation to passive whole-body hyperthermia in the dynamics of exercise performance and endurance of qualified athletes.

\section{Acknowledgements}

The authors are grateful to all volunteers-research participants, and to the company Sybaritic Inc. (USA) for the free granting of Alfa Basic thermo-capsules for hyperthermic sessions. The company and its representatives did not participate in designing the research, collecting, analyzing and interpretation of the data, and the publication preparation.

\section{Authors' Contributions}

OSG and DS-elaborating the research design, summarizing and analyzing the results, preparing the manuscript;

MAZ-performing the spiroergometric examination of the research participants; END—statistical processing and interpreting of the experimental data; SYK-collecting and summarizing the literature sources on the topic, formulating the research hypothesis, reviewing and preparing the final version of the manuscript;

VGS-performing the procedures of passive hyperthermia, examining the athletes, collecting the data.

\section{Funding}

The reported study was funded by RFBR, project number 19-013-00465.

\section{Conflicts of Interest}

The authors declare no conflicts of interest regarding the publication of this paper.

\section{References}

[1] Mero, A., Tornberg, J., Mäntykoski, M. and Puurtinen, R. (2015) Effects of Far-Infrared Sauna Bathing on Recovery from Strength and Endurance Training Sessions in Men. Springerplus, 4, 321. https://doi.org/10.1186/s40064-015-1093-5

[2] Racinais, S., Buchheit, M. and Bilsborough, J. (2014) Physiological and Performance Responses to a Training Camp in the Heat in Professional Australian Football Players. International Journal of Sports Physiology and Performance, 9, 598. https://doi.org/10.1123/ijspp.2013-0284 
[3] Taylor, N.A. and Cotter, J.D. (2006) Heat Adaptation: Guidelines for the Optimization of Human Performance: Review Article. International SportMed Journal, 7, 33-38.

[4] Sawka, M.N., Leon, L.R., Montain, S.J. and Sonna, L.A. (2011) Integrated Physiological Mechanisms of Exercise Performance, Adaptation, and Maladaptation to Heat Stress. Comprehensive Physiology, 1, 1883-1889. https://doi.org/10.1002/cphy.c100082

[5] Meerson, F.Z. and Pshennikova, M.G. (1988) Adaptation to Stressful Situations and Physical Load. Meditsina, Moscow, 224 p. (In Russian)

[6] Gibson, O.R., Taylor, L., Watt, P.W. and Maxwell, N.S. (2017) Cross-Adaptation: Heat and Cold Adaptation to Improve Physiological and Cellular Responses to Hypoxia. Sports Medicine (Auckland, NZ), 47, 1751-1760.

https://doi.org/10.1007/s40279-017-0717-z

[7] Lee, B.J., Miller, A., James, R.S. and Thake, C.D. (2016) Cross Acclimation between Heat and Hypoxia: Heat Acclimation Improves Cellular Tolerance and Exercise Performance in Acute Normobaric Hypoxia. Frontiers in Physiology, 7, 78-88. https://doi.org/10.3389/fphys.2016.00078

[8] Corbett, J., Neal, R.A., Lunt, H.C. and Tipton, M.J. (2014) Adaptation to Heat and Exercise Performance under Cooler Conditions: A New Hot Topic. Sports Medicine, 44, 1323-1331. https://doi.org/10.1007/s40279-014-0212-8

[9] Keiser, S., Fluck, D., Huppin, F., et al. (2015) Heat Training Increases Exercise Capacity in Hot But Not in Temperate Conditions: A Mechanistic Counter-Balanced Cross-Over Study. The American Journal of Physiology-Heart and Circulatory Physiology, 309, 750-758. https://doi.org/10.1152/ajpheart.00138.2015

[10] MacLeave, E.L., Slattery, K.M., Duffield, R., et al. (2017) Temperate Performance Benefits after Heat, But Not Combined Heat and Hypoxic Training. Medicine \& Science in Sports \& Exercise, 49, 509-515. https://doi.org/10.1249/MSS.0000000000001138

[11] Minson, C.T. and Cotter, J.D. (2016) CrossTalk Proposal: Heat Acclimatization Does Improve Performance in a Cool Condition. The Journal of Physiology, 594, 241-242. https://doi.org/10.1113/JP270879

[12] Sotiridis, A., Debevec, T., Ciuha, U., et al. (2018) Heat Acclimation Does Not Affect Maximal Aerobic Power in Thermo-Neutral Normoxic or Hypoxic Conditions. $E_{X}$ perimental Physiology, 104, 345-355. https://doi.org/10.1113/EP087268

[13] Lorenzo, S., Halliwill, J.R., Sawka, M.N. and Minson, C.T. (2010) Heat Acclimation Improves Exercise Performance. Journal of Applied Physiology, 109, 1140-1146. https://doi.org/10.1152/japplphysiol.00495.2010

[14] Karlsen, A., Racinais, S. and Jensen, M.V. (2015) Heat Acclimatization Does Not Improve $\mathrm{VO}_{2 \max }$ or Cycling Performance in a Cool Climate in Trained Cyclists. Scandinavian Journal of Medicine \& Science in Sports, 25, 269-270. https://doi.org/10.1111/sms.12409

[15] Nybo, L. and Lundby, C. (2016) CrossTalk Opposing View: Heat Acclimatization Does Not Improve Exercise Performance in a Cool Condition. The Journal of Physiology, 594, 245-246. https://doi.org/10.1113/JP270880

[16] Horowitz, M. (2010) Genomics and Proteomics of Heat Acclimation. Frontiers in Bioscience, 2, 1068-1080. https://doi.org/10.2741/s118

[17] Iguchi, M., Littmann, A. and Chang, S. (2012) Heat Stress and Cardiovascular, Hormonal, and Heat Shock Proteins in Humans. Journal of Athletic Training, 47, 
184-192. https://doi.org/10.4085/1062-6050-47.2.184

[18] Heathcote, S.L., Hassmen, P., Zhou, S. and Stevens, C.J. (2018) Passive Heating: Reviewing Practical Heat Acclimation Strategies for Endurance Athletes. Frontiers in Physiology, 9, 1851. https://doi.org/10.3389/fphys.2018.01851

[19] Zinchuk, V. and Zhadzko, D. (2012) Sauna Effect on Blood Oxygen Transport and Prooxidant-Antioxidant Balance in Athletes. Medicina Sportiva: Journal of Romanian Sports Medicine Society, 8, 1883-1891.

[20] Hussain, J. and Cohen, M. (2018) Clinical Effects of Regular Dry Sauna Bathing: A Systematic Review. Evidence-Based Complementary and Alternative Medicine, 2, 1-30. https://doi.org/10.1155/2018/1857413

[21] Lee, E., Laukkanen, T. and Kunutsor, S. (2018) Sauna Exposure Leads to Improved Arterial Compliance. Findings from a Non-Randomized Experimental Study. European Journal of Preventive Cardiology, 25, 130-136. https://doi.org/10.1177/2047487317737629

[22] Stanley, J., Halliday, A. and D'Auria, S. (2015) Effect of Sauna-Based Heat Acclimation on Plasma Volume and Heart Rate Variability. European Journal of Applied Physiology, 115, 785-790. https://doi.org/10.1007/s00421-014-3060-1

[23] American College of Sports Medicine (2006) ACSM’s Guidelines for Exercise Testing and Prescription. 7th Edition, Lippincott Williams and Wilkins, Philadelphia.

[24] Nieman, D.C., Lasasso, H., Austin, M.D., et al. (2007) Validation of Cosmed's Fit Mate in Measuring Exercise Metabolism. Research in Sports Medicine, 5, 67-72. https://doi.org/10.1080/15438620601184380

[25] Burtscher, M., Gattere, H., Burtscher, J. and Mairbaurl, H. (2018) Extreme Terrestrial Environments: Life in Thermal Stress and Hypoxia. Frontiers in Physiology, 9, 1-14. https://doi.org/10.3389/fphys.2018.00572

[26] Pallubinsky, H., Schellen, L., Kingma, B.R.M., Dautzenberg, B., Van Baak, M.A. and van Marken Lichtenbelt, W.D. (2017) Thermophysiological Adaptations to Passive Mild Heat Acclimation. Temperature, 4, 176-186. https://doi.org/10.1080/23328940.2017.1303562

[27] Redberg, R. (2015) Health Benefits of Sauna Bathing. JAMA Internal Medicine, 175, 548-554. https://doi.org/10.1001/jamainternmed.2014.8206

[28] Beaudin, A.E., Clegg, M.E., Walsh, M.L. and White, M.D. (2009) Adaptation of Exercise Ventilation during an Actively-Induced Hyperthermia Following Passive Heat Acclimation. American Journal of Physiology-Regulatory, Integrative and Comparative Physiology, 2, 605-611. https://doi.org/10.1152/ajpregu.90672.2008

[29] Kikuchi, H., Shiozawa, N., Takata, S., et al. (2013) Effect of Repeated Waon Therapy on Exercise Tolerance and Pulmonary Function in Patients with Chronic Obstructive Pulmonary Disease: A Pilot Controlled Clinical Trial. International Journal of Chronic Obstructive Pulmonary Disease, 9, 9-16.

https://doi.org/10.2147/COPD.S50860 